\title{
Article
}

\section{Implementing collective leadership in healthcare organisations}

Nightingale, Adele

Available at http://clok.uclan.ac.uk/31707/

Nightingale, Adele (2020) Implementing collective leadership in healthcare organisations. Nursing standard, 35 (2). ISSN 0029-6570

It is advisable to refer to the publisher's version if you intend to cite from the work. http://dx.doi.org/10.7748/ns.2020.e11448

For more information about UCLan's research in this area go to http://www.uclan.ac.uk/researchgroups/ and search for < name of research Group>.

For information about Research generally at UCLan please go to http://www.uclan.ac.uk/research/

All outputs in CLoK are protected by Intellectual Property Rights law, including Copyright law. Copyright, IPR and Moral Rights for the works on this site are retained by the individual authors and/or other copyright owners. Terms and conditions for use of this material are defined in the policies page.

\section{CLoK}

Central Lancashire online Knowledge www.clok.uclan.ac.uk 


\title{
Collective leadership in nursing teams
}

\author{
Adele Nightingale
}

\section{Citation}

Nightingale A (2020) Collective leadership in nursing teams. Nursing Standard. doi: 10.7748/ns.2020.e11448

\begin{abstract}
Peer review
This article has been subject to double-blind peer review and checked for plagiarism using automated software
\end{abstract}

Correspondence

anightingale@uclan.ac.uk

[Q are you OK for us to publish your email address for correspondence? Also, do you have a Twitter handle we could add?] Yes

Twitter: @Deli_1102

Conflict of interest

None declared

Accepted

14 August 2019

Published online

Xxxxxxx

\section{Abstract}

Leadership is one of the most discussed concepts within healthcare. It is well established that leadership is linked to patient safety and this has been demonstrated for several years through high-profile reports investigating suboptimal care in healthcare organisations. Because of the importance of leadership within healthcare, it is essential that nurses understand the term leadership and what it means to healthcare practice. There is a drive for leadership at all levels of healthcare organisations. This article will explore how leadership at all levels is accomplished using collective leadership and outlines the behaviours and qualities required to develop and sustain this approach to leadership.

\section{Author details}

Adele Nightingale, senior lecturer, healthcare leadership practice, School of Health Science, University of Central Lancashire, Lancashire, England

Key words 
Collective Leadership, qualities, skills, behaviours, influence, relationships, patient safety, teamwork, culture.

Over the last decade, several high-profile reports have investigated suboptimal care within the NHS, such as the Report of the Mid Staffordshire NHS Foundation Trust Public Inquiry (Francis 2013). While these reports feature a variety of recommendations, a common theme across them all are suggestions for improving the leadership at all levels from the ward to the boardroom [Q is this the leadership at the top of the organisation e.g. the managers, MDs etc., or further down such as lead nurses, doctors etc.?]. The Francis report (2013) described senior, leaders who were ineffective when it came to tackling challenges, contributed a negative workplace culture, did not communicate effectively and lacked accountability. A Promise to Learn, A Commitment to Act: Improving the Safety of Patients in England (Berwick 2013) considered the lack of effective leadership behaviour and detailed how leadership was deficient [Q whereabouts was it deficient? Similar $\mathbf{Q}$ to the previous one!], and how there was a predisposition to display behaviours that increased the risk of harm and made healthcare less safe. These behaviours included a culture of blame, not listening and not responding to concerns raised [Q any examples of behaviours that we could add here, just for clarity?]. These suboptimal leadership behaviours specified by Francis (2013) and Berwick (2013) were ultimately contributing factors to patient deaths in the NHS

The Report of the Morecambe Bay Investigation (Kirkup 2015) also identified ineffective leadership as a significant contributing factor to the suboptimal care experienced by patients. A consequence of these cases was the publication of the document Culture Change in the NHS: Applying Lessons of the Francis Inquiries (Department of Health 2015). One of the messages that came from this publication was that the values of the NHS should be applied at all levels of an organisation, with leaders leading by example.

Throughout these reports there is discussion alluding to inadequate leadership, strong leadership, and effective leadership, so it is important to have a working definition of the term leadership. This article then explores the concept of collective leadership, how it fits within the current NHS, and the benefits it can bring to practice.

\section{Definitions of leadership}

Throughout the literature, there are several definitions of leadership, but there is a lack of consensus (Beerel 2009, Gill 2011, Ellis and Bach 2015, Northouse 2016). This may be because leadership is a term that is applicable to several different areas, including business, politics and religion. It is a term studied since the early 19th century, but the words that form the stem of leadership came much earlier in the 13th century when 'lead' and 'leader' were first described [Online Etymology Dictionary, 2019) Q could you provide a reference for this sentence?]. The word 'lead' is associated with guiding and showing the way and the term 'leader' is related to one who leads.

Leadership as a term came later and its meaning has evolved over time to maintain its relevance in modern society. Leadership was originally related to the position of a leader and commander, however this has now become a term that relates to the characteristics necessary to be a leader and the capacity to lead (Online Etymology Dictionary 2019). This demonstrates that historically leadership was associated with a designated position or title of leader, and that it has changed, with leadership now described with charisma, vision and transformation as significant words (Gill 2011) [Q are these words used to describe all types of leadership, or just one particular type]. These words describe leadership, however there is a tendency to complicate this word by then adding adjectives to describe the leadership. These descriptors are numerous and forever evolving. This is a contributing factor in the lack of succinct definition of leadership and why it is important that we have a common understanding of the term 
Qualities, values and behaviours of oneself and others including being inspirational, motivating self and others, being visionary, having empathy and compassion [Q which qualities, values and behaviours? Any examples you could add?] are recognised as essential requirements of an effective leader (Goleman 1995, Gill 2011) [Q could you add the Goleman reference to the reference list?]. Self-awareness is a quality that facilitates the development of leaders who are adaptable and can see the perspective of others (Cummings 2014). The NHS Leadership Academy (2016) supports this concept, suggesting leadership is based on skills, behaviours and experiences that can be developed, supported and improved. Using all of the referenced material, the working definition for this article is that leadership is 'the action of influencing others using positive qualities, behaviours and interpersonal skills shaped by personal and professional values'. [Q is this referenced anywhere, or is this your own definition based on collating all the information from referenced material?] This is my working definition, synthesis informed by the literature

Leadership becomes more complex when split into its many constituents or types of leadership demoted by the adjective that describes leadership [Q is this referring to types of leadership? Or characteristics? Or something else?]. Leadership literature discusses leadership theories, such as transactional, transformational, and contingency; leadership styles such as Daniel Goleman's six styles; leadership qualities, and skills and behaviours [Q could you add more detail here on some of the alternative theories? It would just help give a clearer picture of the current leadership landscape and how they fit within healthcare]. I could, but it will detract from the point and add confusion!Winston and Patterson (2006) explain that there are 93 dimensions that comprise the whole of leadership. There are several adjectives that describe leadership, such as compassionate, medical, and clinical, suggesting that leadership is a complex phenomenon. To ensure that leadership adds value at patient, team, departmental and organisational level in the NHS it is necessary to articulate what it is, what it looks like and how it is enacted, actioned and the consequences of ineffective leadership.

\section{As suggested earlier there are numerous pieces of literature that relate to leadership. The current approach that is 'in vogue} in the NHS is that of collective leadership.

[Q could you add a short paragraph here as a way of linking the preceding information with what is to follow on collective leadership? At the moment the article jumps into collective leadership with little introduction. For example, is this a leadership theory or a leadership style? How prevalent is it within the NHS? How does it compare to others types? This, combined with one of the earlier queries on other leadership styles, should help give things a bit more context]

[Q could you add a definition of vertical leadership here? We mention it in the next section but it's more as a comparison to collective leadership - it never gets defined at any point]

Collective leadership

West et al (2014) [Q could you add this reference to the reference list?] consider that collective leadership is a type of leadership culture that where formal and informal leaders work together to generate actions. This definition relates the term to that of an action or actions, and it establishes that it is something that can be performed by staff in an organisation that have leadership roles, but that can also be a task undertaken by those without a title or position. Therefore, collective leadership will involve staff with formal leadership roles, but also those influential leaders who do not have a designated title.

It differs from a vertical leadership, where there is a hierarchy at the top who make decisions to cascade to other for implementation as it represents leadership from the bottom and the middle (Heimans and Timms 2018), while vertical leadership features one person at the top in a formal leadership role acting as a leader. Collective leadership recognises the move away from this vertical representation of actions and interaction of 'the leader' to recognising and valuing the

Commented [AN< OS\&HS2]: This was never intended to be a paper about leadership styles and theories and I wouldn't write one about that as there are so many written and it would just be a regurgitation of other peoples work which I don't feel is helpful and just adds to the 'fluffiness' of leadership. 
emerging and informal contribution provided by members of the wider team (Friedrich et al 2009). However, collective leadership is not about having no central leader figure. There will need to be a person that has the capacity [Q any examples of a person like this?] to develop an environment that is conducive to collective leadership, for example a matron, charge nurse team leader. An individual is required to develop a cohesive team guided by shared attitudes, expectations and goals, and clarify the objectives of the team. It is also not about the quality and numbers of the formal leaders - those with designated roles - as the focus is on the unity of the formal and informal leaders and their ability to work collaboratively and to align to the vision of the organisation (Eckert et al 2014)

The goal of collective leadership is to develop a workplace culture where responsibility and accountability function simultaneously, focusing on the leadership capacity of the team as opposed to individuals (McAuliffe 2017). West et a (2014) expresses that leadership itself is not about the person leading, but it is about the relationships that they establish and how those relationships work. For relationships to work [Q what does this mean in the context of collective leadership? What is relationship that works? What is one that doesn't work?] within collective leadership there should be respect of each other's role, responsibility and the skills and expertise associated with this. For example, if you work on a ward do you know the value and expertise of a physiotherapist or occupational therapist? Consider their areas of expertise, their knowledge and skills and how they can complement, enhance and optimise the care delivered within your nursing team. Leadership, the ability to influence others, will at times lie with professionals outside of your team, department and profession. It is necessary to recognise this to prevent personal and professional conflict and to create an environment that is conducive to delivering safe and effective care to patients.

Collective leadership can fit within today's NHS, where there is a drive for all staff to take responsibility for the success of the organisation (Eckert et al 2014). This can be achieved by developing leaders at all levels within an organisation. The concept of collective leadership is that leadership will align with the person's role and responsibility. Each person will take individual and collective responsibility for the organisation at a personal level, team level and departmental level. [Q what does this mean in practice? Do you have any examples to clarify the point? See point above ] To support this the NHS have developed the NHS Healthcare Leadership model (NHS Leadership Academy 2013), which is a tool that enables staff to aspire to leadership irrespective of their position within the organisation. The model is designed to support staff to become better leaders by describing the positive actions of leaders and how these can be developed. The emphasis is on individuals as leaders rather than those with formal leadership roles. This model has a complementary self-assessment tool, and alongside this is a 360-degree feedback tool that provides insight into colleagues' perceptions of staff members' leadership behaviours and abilities. The 6 values in the NHS Constitution, including respect, dignity, compassion, quality, improving lives and everyone counts (Health Education England, 2019) [Q what are these values?] underpin the NHS Healthcare Leadership model, and although it was published in 2013, it is not static and is designed to evolve with changes in the NHS [Q any examples of how it may have changed already, given it was published six years ago?] The model itself has not changed since design, but context in which it will be used has. This is why it is important to review the self-assessment tool as you will develop with experience, your job role and responsibilities will evolve and the environment in which you work will change.

\section{Implementing collective leadership within practice}

Friedrich et al (2009) describes collective leadership as 'a dynamic leadership process in which a defined leader or set of leaders selectively utilise skills and expertise within a network, effectively distributing elements of the leadership role as the situation or problem at hand requires'. To undertake this there is a need for healthcare teams to find those with the most expertise. They should consider who the experts are and recognise that staff with formal leadership roles will need to step back and take the role of follower where there is a person with increasing expertise [Q could you provide an example related to clinical practice? The point has now been made above ]. Recognising staff members' strengths and areas of 
expertise will aid the development of diverse teams and increase opportunities to develop a collective leadership approach to care (Friedrich et al 2009)

West et al (2014) states that to implement collective leadership effectively, power needs to be distributed where the expertise lies. The challenge, therefore, for healthcare teams is recognising the experts. To recognise expertise will require respect of each other's roles and responsibilities - some areas will be obvious i.e surgeon and nurse, others more subtle nursing associate and assistant practitioner [Q any examples here of subtle areas to look out for?]. To respect other professionals as experts there is a need for teams to work together across professional boundaries. For example, sharing success and demonstrating what expertise looks like is a proactive means of identifying areas of optimal practice [Q how would this be achieved in a clinical setting?] this could be done by the Trust news letters, Trust Award systems, sharing success at team meetings. Recognising and sharing optimal practice develops a platform for staff to collaborate, connects the organisation and is a means of motivating and inspiring others (Eckert et al 2014).

As well as distributing power towards expertise, West et al (2014) notes that it needs to be distributed where staff are capable and motivated. However, while staff need to be capable, it is important for leadership development strategies to be in place, to develop and sustain leaders of the future. The concept requires a commitment from staff and for them to feel that their contributions are respected, recognised and valued [Q is the implication here that having development strategies will make staff feel more committed, with their contributions respected?]. yes

Collective leadership is associated with developing an organisational culture in which high quality compassionate care is the standard [Q could you provide a reference for this?]. To achieve this organisations need to ensure multi-level collaboration between teams and that resources are allocated [Q You mention time in the next sentence, but are there any other resources that collective leadership requires?]. For example, staff require the time and space to implement the various aspects of the concept, the opportunity, time and space to meet as multi professional teams, opportunities to be educated together to encourage a shared vision that is aligned to that the NHS/Trust Collective leadership will vary depending on where a person sits within an organisation. Staff members at different levels or functions within the organisation will have varying experiences. For example, a Matron on a ward may have less patient contact and more managerial responsibilities due to the nature of their role and will therefore rely on her clinical experts (band $5,6,7)$ to make decisions about patient care. The lower bands are now the leaders as they have the expertise and experience, couple this with motivation and time and it brings collective leadership to life.Q do you have any examples here? This is an interesting point that could do with expansion]

It is essential to recognise how power changes between teams if collective leadership is to be successfully implemented. [Q could you clarify what you are trying to say here. Is it that within collective leadership the individual with the authority to make decisions will change depending on who has the expertise at a given moment, as per the next sentence?] Yes- the example that I have in putted above will clarify this? It can be situational and dependent on who has the expertise at that moment. To develop the concept of collective leadership there should be an understanding of boundaries. It is important to recognise your own professional boundaries, role boundaries and personal boundaries and ensure that these are maintained. To do this we need to recognise our own scope of practice and that of other professionals, if we are not aware of this we can ask, we can challenge and we can offer our support where it is needed if we recognise that there are deficits in other knowledge and skills. [Q what sort of boundaries are in place when collective leadership is used? Is this referring to staff members knowing when they are expert in something and when they are not? And how does it relate to the ebb and flow of power between teams? Because we talk about working across professional boundaries in a paragraph above this] 
Although the concept is not new, this type of leadership culture is not common throughout healthcare [Q could you provide a reference for this?]. There are small areas of excellent practice where a collective leadership approach to quality improvement has had a significant impact (West et al, 2014) [Q could you clarify what you mean by this. Are you referring to good practice in terms of collective leadership being implemented?], but these have not led to a cultural shift in the workplace IQ in terms of moving the type of leadership within the NHS? If that's correct, could you provide a reference?].addressed in the point above Therefore, to ensure collective leadership develops throughout an organisation, it is necessary for teams to have clear team or organisational goals and to transmit the message to all members of an organisation and not just those with formal leadership roles. For healthcare teams to be inclusive and recognise the value of informal leaders, these informal leaders should understand that they have permission to lead, they should be asked for and offer their opinions and ideas. We are autonomous practitioners and leadership starts with self. Consider if you have the positive qualities and behaviours and the ability to influence others, this may not be evident until you start to put ideas forward and have the self-confidence to offer a different perspective on ideas. [Q what does this mean in practice? Could you offer an example where this might happen?]

\section{How collective leadership can improve practice}

The concept of leadership at all levels is that every member of staff will be responsible for the organisation, thereby moving working practice away from a blame culture. If each individual is responsible and accountable for their actions, rather than apportion blame when incidents occur, we create a positive culture where it is safe to highlight errors or near miss, but in a supportive environment where we can share and learn from mistakes, putting strategies in place to prevent reoccurence [Q could you expand on this a bit and describe how having every staff member responsible moves away from a blame culture? And also, what does it move it towards?]. Collective leadership encourages safe practice, because with all staff members empowered to lead it promotes a workplace where staff feel they can raise concerns and challenge unsafe behaviour [ $Q$ have reworded, does this still retain your original meaning?].yes These skills are identified by Francis (2013) as being either missing or not valued and acted upon in his report on the challenges encountered by Mid Staffordshire NHS Foundation Trust.

Effective communication is required to support staff to raise concerns, have challenging conversations and be accountable for their actions. This includes active listening and listening to learn and gain insight. In busy environment like healthcare there is a tendency to listen to respond rather than listen to understand (Covey, 2004). Active listening encourages empathy by being present rather than distracted (e.g., not looking at mobile phones whilst conversing with others) and checking your understanding by repeating what you heard (which can be different than what was said)could you provide some definitions of what these are and examples related to nursing? For instance, how does effective communication ultimately lead to, or help, staff be accountable for their actions?]. Having challenging conversations requires teams to demonstrate compassion by being empathetic, as empathy will engage and encourage staff to be open, feel valued and listed to[Q encourage them to do what?]. West (2017) suggests that compassion develops a psychological space in which staff will work collaboratively and co-operatively as they will feel empowered and supported to implement new ideas or ways of working and will be increasingly confident in speaking out against suboptimal practice. [Q what's the implication of this for collective leadership?] The implication of this to collective leadership is that it will create a cohesive team that understands, supports each other whilst working towards the common goal of optimising patient safety.

\section{Accountability in a collective leadership model}

Although collective leadership operates using a method whereby informal and formal leaders work together to generate

actions, it is important to recognise that there should be a level of capability, motivation and accountability amongst all staff 
[Q for whom, and where? Presumably among all staff]. The distribution of power, authority and decision-making discussed in this article does not absolve one person from accountability but ensures a shared accountability in an environment where each person is responsible for their actions. [Q could you give an example of how this would work in practice, relating to shared accountability?] All registered practitioners are accountable for their acts and omissions, but this level of accountability should not just extend to registered practitioners. All NHS workers are accountable to their Trusts and have a responsibility, when necessary to justify their actions.

To ensure the presence of capable staff members, there is a need to recognise skills within teams and organisations and provide individuals opportunities so that they can develop these skills, and feel valued and supported to lead (Friedrich 2009, West 2017) [Q there's no Friedrich 2016 reference in the reference list. Is this meant to be 2009, or is it a new reference?]. However, it is essential to have strategies in place whereby those who demonstrate a lack of capability are accountable for their actions, these strategies will included Human Resource policies, for example a supportive capability policy [Q what strategies can organisations have in place for this?]. It is necessary to address suboptimal leadership behaviours via the appropriate channels for example via appraisal systems [Q could you provide a quick example of an appropriate channel?] in an open, honest, and transparent manner that is supportive, non-punitive and where lessons can be learned [Q is this lessons being learned from suboptimal practice- yes? Or something else?] to enhance effective patient care

\section{Ensuring collective leadership evolves with change}

It is important to recognise that leading is an evolving dynamic that needs to change as the NHS changes. While formal or informal leaders may be capable, motivated and recognised as experts, it does not mean that they do not need to evaluate their skills and expertise on a regular basis. A change in role and responsibility will lead to a shift in power and authority, resulting in a change of team dynamics, this could manifest in a team where a member of staff receives promotion from a band 6 to band 7. With that promotion will come a change in role and responsibility, it may cause conflict, there could be jealousy. could you provide an example of a role within a team that can change the team dynamics within collective leadership?]. This will influence how the collective leadership within the team functions. Therefore, there is a requirement to have a means for self-evaluation, team evaluation and consideration given to the sustainability of collective leadership. Having a model whereby responsibility and accountability function simultaneously at both collective and individual level leads to a culture in the workplace to drive continuous improvement (Eckert et al 2014).

\section{Conclusion}

Collective leadership, if deployed effectively, empowers staff at all levels within an organisation to take ownership of their personal and team leadership qualities, skills and behaviours. It is a progressive and developmental approach to leadership that is inclusive of all. It is based on relationships, social influence, qualities and behaviours. Recognising this approach facilitates teams to embed the values of the NHS throughout their delivery of compassionate care to patients and staff alike. The concept is used for personal and professional growth within healthcare teams, promote accountability and support the move away from a culture of blame to one that is fair. [Q what would this move it towards? Very similar to the query earlier].

\section{References}

Beerel A (2009) Leadership and Change Management. Sage Publications, London 
Department of Health (2015) Culture Change in the NHS: Applying the Lessons of the Francis Inquiries.

https://www.gov.uk/government/uploads/system/uploads/attachment_data/file/403010/culture-change-nhs.pdf (Last accessed 16 August 2019.)

Eckert R, West M, Altman D et al (2014) Delivering a Collective Leadership Strategy for Healthcare.

https://www.kingsfund.org.uk/sites/defaultfiles/media/delivering-collective-leadership-ccl-may.pdf (Last accessed 16 August 2019.)

Ellis P, Bach S (2015) Leadership, Management and Team Working in Nursing. Second edition. SAGE Publications, London.

Francis R (2013) Report of the Mid Staffordshire NHS Foundation Trust Public Inquiry. https://www.gov.uk/government/publications/report-of-the-midstaffordshire-nhs-foundation-trust-public-inquiry (Last accessed: 16 August 2019.)

Friedrich TV, Vassey WB, Schuelke MJ et al (2009) A framework for understanding collective leadership: the selective utilisation of leader and team expertise within networks. Leadership Quarterly. 20, 6, 933-958. doi: 10.1016/j.leaqua.2009.09.008

Gill R (2011) Theory and Practice of Leadership. Second edition. SAGE Publications, London

Heimans J, Timms H (2018) New Power. New York. Anchor Books [Q could you link to the version of the book you referenced? There seem to be a couple around with slightly different titles] https://thisisnewpower.com/

Kirkup B (2015). The Report of the Morecambe Bay Investigation

https://assets.publishing.service.gov.uk/government/uploads/system/uploads/attachment_data/file/408480/47487_MBI_Accessible_V0.1.pdf (Last accessed: 16 August 2019.)

McAuliffe E, De Brún A, Ward M et al (2017) Collective leadership and safety cultures (Co-Lead): protocol for a mixed-methods evaluation of the impact of a co-designed collective leadership intervention on team performance and safety culture in a hospital group in Ireland. BMJ Open. 7,11 doi: 10.1136/bmjopen-2017-017569

NHS Leadership Academy (2013) Healthcare Leadership Model: The Nine Dimensions of Leadership Behaviour.

https://www.leadershipacademy.nhs.uk/wp-content/uploads/2014/10/NHSLeadership-LeadershipModel-colour.pdf (Last accessed: 16 August 2019.)

NHS Leadership Academy (2016) Better Leaders, Better Healthcare: 2016 Programme Guide. https://www.leadershipacademy.nhs.uk/wpcontent/uploads/2016/01/BW NHS-Leadership-Academy-Programme-Guide.pdf (Last accessed 16 August 2019.)

Northouse P (2016) Leadership: Theory and Practice. Seventh edition. SAGE Publications, London

Online Etymology Dictionary (2019) Leadership (n.) https://www.etymonline.com/word/leadership\#tetymonline_v 30153 (Last accessed (16 August 2019. )

West M (2017) Compassion and Innovation in the NHS https://www.kingsfund.org.uk/blog/2017/09/compassion-and-innovation-nhs. (Last accessed: 16 August 2019)

West M, Eckert R., Steward K., Passmore B. (2014) Developing Collective Leadership.

http:/ Eww ctrtraining Ko

Winston BE, Patterson K (2006) An integrative definition of leadership. International Journal of Leadership Studies. 1, 2, 6-66 